\title{
Optimasi Distribusi Produk Menggunakan Metode Cheapest Insertion Heuristic Berbasis Web
}

\author{
Kadek Meliantari, Dwi Putra Githa, Ni Kadek Ayu Wirdiani \\ Jurusan Teknologi Informasi, Fakultas Teknik, Universitas Udayana \\ e-mail: kadek meliantari@yahoo.com, dwiputragitha@gmail.com, ayu werdi@yahoo.com
}

\begin{abstract}
Abstrak
Tingginya permintaan distribusi menyebabkan pendistribusian harus dilakukan setiap hari. Kurir harus memperkirakan ururtan rute perjalanan karena banyak lokasi yang harus dikunjungi dalam satu kali pendistribusian. Perkiraan urutan rute perjalanan secara acak menyebabkan tingginya biaya dan lamanya waktu perjalanan distribusi sehingga diperlukan solusi yang dapat memberikan rute perjalanan optimal agar dapat menghemat biaya dan waktu pendistribusian. Penelitian ini membangun sebuah sistem untuk optimasi rute perjalanan distribusi. Metode yang digunakan adalah Cheapest Insertion Heuristic yakni metode untuk mencari jarak terkecil melalui perulangan dengan menyisipkan nilai baru hingga membentuk rute perjalanan yang optimal. Sistem ini memvisualisasikan hasil rute perjalanan distribusi menggunakan Google Maps. Hasil dari pengujian yang dilakukan terhadap proses penentuan rute distribusi pada sebuah perusahaan adalah sistem optimasi distribusi produk menggunakan Metode Cheapest Insertion Heuristic menghasilkan rute perjalanan yang lebih optimal dari segi total jarak dan waktu tempuh perjalanan.
\end{abstract}

Kata kunci: Distribusi, Optimasi Rute, Cheapest Insertion Heuristic

The high distribution demand causes distribution to be done every day. Couriers must estimate the travel route because many locations must be visited in one distribution. Estimates of random travel route sequences lead to high costs and length of distribution trip time so solutions are needed that can provide optimal travel routes in order to save costs and distribution time. This research builds a system for optimization of distribution route. The method used is Cheapest Insertion Heuristic which is a method to find the smallest distance through looping by inserting a new value to form an optimal travel route. This system visualizes the results of distribution travel routes using Google Maps. The results of the testing carried out on the process of determining the distribution route in a company is a product distribution optimization system using the Cheapest Insertion Heuristic Method to produce a more optimal travel route in terms of total distance and travel time

Keywords : Distribution, Route Optimization, Cheapest Insertion Heuristic

\section{Pendahuluan}

Distribusi merupakan proses pengiriman suatu produk yang dilakukan dari satu pihak ke pihak lain [1]. Perusahaan penghasil produk menjual produk ke distributor, kemudian distributor menjual produk ke pengecer atau pelanggan. Proses penyaluran produk dari pabrik ke distributor memerlukan transportasi. Transportasi dalam proses distribusi sangat menentukan keberhasilan pengiriman produk ke lokasi distributor dengan jumlah yang sesuai, kondisi produk yang baik dan waktu yang tepat.

Pengiriman yang tepat waktu merupakan salah satu tujuan dari proses distribusi yang dapat dilakukan dengan memahami lokasi tujuan distribusi. Lokasi yang dituju dalam pendistribusian tidak pada satu lokasi saja melainkan menuju banyak lokasi. Pendistribusian menuju banyak lokasi membutuhkan biaya transportasi yang cukup tinggi bahkan melebihi biaya yang dianggarkan. Biaya transportasi yang melebihi anggaran dapat dikarenakan penentuan rute pendistribusian masih dilakukan secara manual atau acak yaitu penentuan jalur distribusi berdasarkan perkiraan saja.

Sistem Informasi Geogafis merupakan sistem informasi yang memiliki kemampuan dalam membangun, menyimpan, mengelola dan menampilkan informasi bereferensi geografis 
[2]. Teknologi sistem informasi geografis dapat digunakan untuk membangun rute dengan memanfaatkan Google Maps agar dapat meminimalisir permasalahan distribusi [3]. Permasalahan dalam proses distribusi disebut Travelling Salesman Problem (TSP) yakni pencarian rute distribusi paling optimum dalam suatu perjalanan yang mencari jarak terpendek untuk mencapai lokasi tujuan. TSP dapat di selesaikan dengan menggunakan Algoritma Cheapest Insertion Heuristic $(\mathrm{ClH})$. Algoritma ini memiliki konsep menyisipkan kota yang belum terlewati dengan tambahan jarak minimum hingga semua kota terlewati untuk mendapatkan solusi [4].

Penelitian yang terkait dengan optimasi rute diantaranya penelitian [5] yang membahas mengenai cara penentuan rute untuk meminimasi jarak dan waktu penyelesaian setiap kegiatan distribusi tabung gas menggunakan Metode (1-0) Insertion Intra Route. Kajian [6] melakukan penelitian mengenai pencarian rute terpendek pada aplikasi berbasi peta untuk berbagai keperluan masyarakat yang saat ini dihadapkan kepada kesulitan transportasi seperti kemacetan jalan raya. Hasil pengujian dengan membuat beberapa rute dan perbandingan perhitungan telah menunjukkan hasil rute yang tepat sesuai dengan kondisi di lapangan. Kajian [7] melakukan penelitian untuk minimasi biaya dalam pengiriman produk minuman dengan cara melakukan penjadwalan dan penentuan rute pengiriman menggunakan Metode Savings Matrix. Kajian [8] melakukan penelitian untuk menentukan distribusi air minum yang optimal dengan biaya distribusi yang minimum menggunakan Metode Least Cost dan Metode Modified Distribution. Kajian [9] melakukan penelitian yang membahas perbandingan antara algoritma Cheapest Insertion Heuristic dan Ant Colony System mengenai kecepatan waktu proses distribusi.

Mengacu dari permasalahan distribusi yang telah dijelaskan sebelumnya dan penelitian terkait maka dibangun sebuah sistem optimasi rute distribusi produk menggunakan Metode Cheapest Insertion Heuristic berbasis web. Sistem optimasi bertujuan untuk menemukan rute perjalanan yang optimal secara otomatis berdasarkan jarak sehingga dapat meminimalisir penggunaan bahan bakar dan waktu tempuh perjalanan. Metode yang dipergunakan untuk memperoleh rute perjalanan yang optimal yaitu Cheapest Insertion Heuristic. Rute yang dihasilkan dari algoritma Cheapest Insertion Heuristic merupakan rute dengan jarak terpendek yang divisualisasikan melalui Google Maps untuk mempermudah kurir menentukan jalur dalam menyelesaikan proses distribusi.

\section{Metodologi Penelitian}

Metodelogi penelitian membahas mengenai tahapan penelitian dan gambaran umum dari sistem informasi geografis optimasi distribusi.

\subsection{Tahapan Penelitian}

Tahapan yang digunakan dalam penelitian ini adalah tahap pengumpulan data, tahap perancangan dan tahapan penyusunan laporan. Gambaran tahapan penelitian dapat dilihat pada diagram alir pada Gambar 1. 


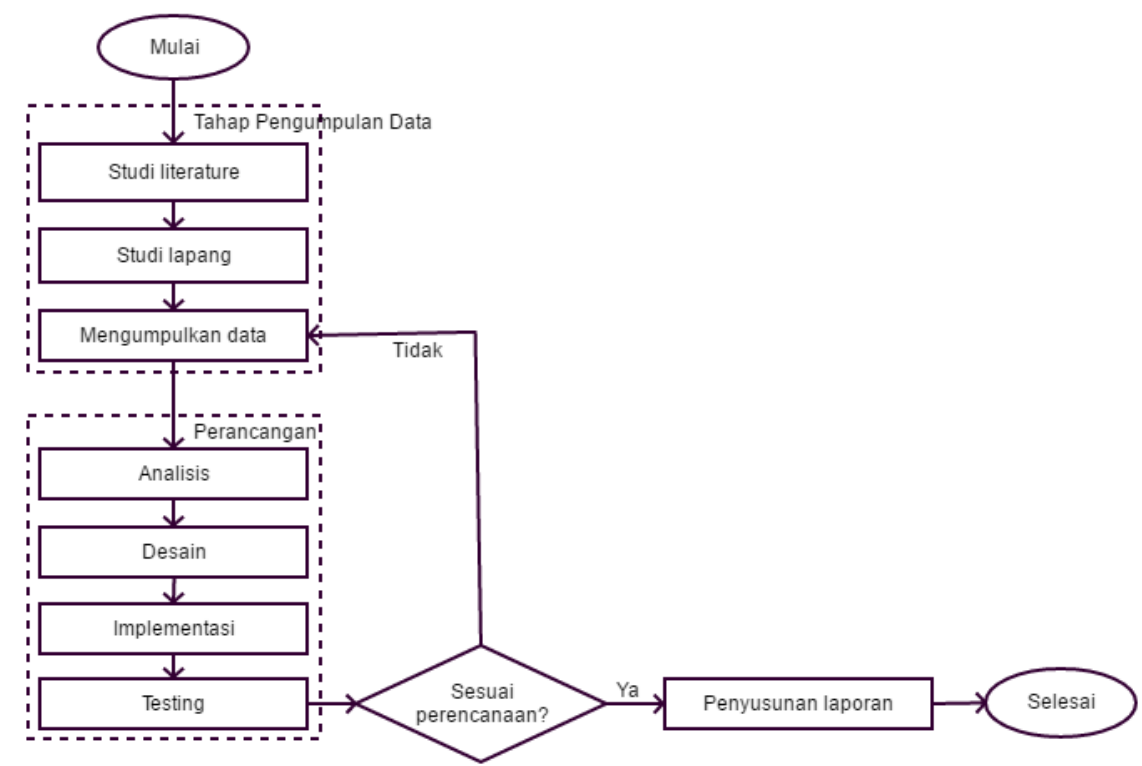

Gambar 1. Tahapan Penelitian

Langkah awal yang dilakukan dalam penelitian ini adalah tahapan pengumpulan data yakni melakukan identifikasi masalah yang terdapat dalam sebuah perusahaan. Permasalahan yang ditemukan setelah diidentifikasi yaitu kurir kesulitan menentukan rute distribusi dikarenakan tujuan distribusi yang cukup banyak. Data yang dikumpulkan untuk tahap studi lapangan yaitu data lokasi distributor dan data urutan rute perjalanan ke beberapa lokasi. Tahapan studi literatur dilakukan untuk mencari metode yang akan digunakan menentukan rute optimal yaitu Metode Cheapest Insertion Heuristic $(\mathrm{ClH})$. Tahap perancangan yaitu melakukan analisis terhadap data distributor dengan perhitungan menggunakan metode $\mathrm{ClH}$. Tahapan desain dilakukan setelah mengetahui bahwa metode $\mathrm{ClH}$ menghasilkan rute perjalanan yang optimal dibandingkan dengan data rute perjalanan yang didapat pada tahapan pengumplan data. Desain sistem dirancang sesuai dengan kebutuhan agar dapat menghasilkan rute perjalanan optimal. Tahapan selanjutnya yaitu implementasi pembuatan program sesuai desain yang telah dirancang. Tahapan testing dilakukan untuk memeriksa apakah sistem yang dibuat telah sesuai dengan perencanaan yaitu menghasilkan rute perjalanan yang optimal. Tahapan yang terakhir adalah tahap penyusunan laporan dimana tahapan ini dilakukan ketika semua tahapan sebelumnya telah berhasil diselesaikan.

\subsection{Gambaran Umum Sistem}

Sistem optimasi distribusi menggunakan Metode Cheapest Insertion Heuristic $(\mathrm{CIH})$ berbasis web merupakan sistem yang diperlukan bagi perusahaan yang melakukan proses distribusi. Gambaran umum dari sistem optimasi distribusi yaitu sebagai berikut.

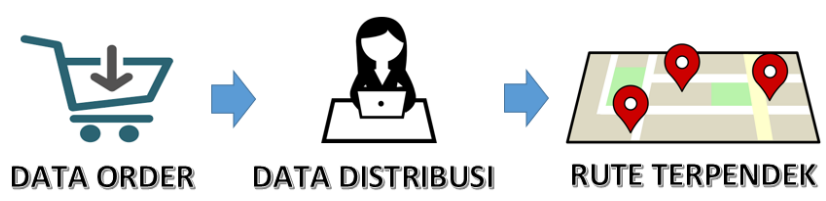

Gambar 2. Gambaran Umum Sistem

Gambar 2 merupakan gambaran umum sistem optimasi distribusi, terdapat beberapa proses yaitu melakukan input data order kemudian input data distribusi sehingga menghasilkan rute terpendek. Input data order dilakukan oleh admin toko, admin toko yang dimaksud adalah admin dari setiap distributor yang melakukan pemesanan produk. Data order yang masuk kemudian direspon oleh admin gudang, tugas dari admin gudang adalah melakukan input data distribusi setelah beberapa data order masuk. Input distribusi dilakukan untuk menghasilkan rute dengan jarak yang paling pendek. Rute terpendek yang dihasilkan sistem digunakan oleh kurir sebagai petunjuk untuk melakukan distribusi. 


\section{Kajian Pustaka}

Kajian pustaka sebagai penunjang pembangunan optimasi distribusi menggunakan Metode Cheapest Insertion Heuristic berbasis web yaitu sebagai berikut.

\subsection{Distribusi}

Distribusi dapat diartikan sebagai kegiatan pemasaran yang berusaha memperlancar dan mempermudah penyampaian barang dan jasa dari produsen kepada konsumen. Produsen atau perusahaan penghasil suatu produk mengirimkan atau sekaligus menjual ke suatu distributor dan distributor tersebut kemudian menjual produk ke pengecer atau pelanggan. Saluran distribusi dapat menentukan berhasil tidaknya pemasaran yang dilakukan oleh sebuah perusahaan, oleh karena itu sebuah saluran distribusi yang efektif dapat lebih menunjang pelaksanaan pemasaran yang efektif pula [10].

\subsection{Cheapest Insertion Heuristic (CIH)}

Algoritma ini memiliki konsep menyisipkan kota yang belum terlewati dengan tambahan jarak minimum hingga semua kota terlewati untuk mendapatkan solusi permasalahan. Sebuah perjalanan (tour) Algoritma CIH dimulai dari simpul awal (1) menuju ke semua simpul $(2,3, \ldots, n)$ dan kembali ke simpul awal (1) tanpa ada simpul yang dikunjungi lebih dari satu kali dengan memperhitungkan tambahan jarak minimum ketika satu simpul disisipkan ke dalam partial tour yang ada. Berikut ini adalah tata urutan algoritma $\mathrm{ClH}$ [11].

1. Permasalahan dapat direpresentasikan ke suatu grafik lengkap.

2. Penelusuran di mulai dari sebuah kota pertama yang dihubungkan dengan sebuah kota terakhir.

3. Hubungkan 2 kota tersebut dengan sebuah subtour. Subtour adalah perjalanan dari kota pertama dan berakhir di kota pertama sehingga membentuk sebuah sikel, misal $(1,2) \rightarrow(2,3) \rightarrow(3,1)$ yang ditunjukan pada Gambar 3 .

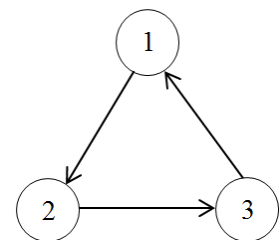

Gambar 3. Contoh Subtour

4. Subtitusi salah satu arah hubungan (arc) dari dua kota dengan kombinasi dua arc, yaitu $\operatorname{arc}(\mathrm{I}, \mathrm{j})$ dengan $\operatorname{arc}(\mathrm{l}, \mathrm{k})$ dan $\operatorname{arc}(\mathrm{k}, \mathrm{j})$, dengan $\mathrm{k}$ merupakan kota sisipan dengan tambahan jarak terkecil, yang diperoleh dari :

$$
C j k=C i k+C k j-C i j
$$

Keterangan :

1) Cik adalah jarak dari kota $i$ ke kota $\mathrm{k}$

2) Ckj adalah jarak dari kota k ke kota j

3) Cij adalah jarak dari kota i ke kota j

4) Ulangi langkah 4 sampai seluruh kota masuk dalam subtour sehingga algoritma di hentikan.

\subsection{Google Maps \& Google Maps API}

Google Maps diperkenalkan pada tahun 2005 yang menyediakan pemetaan aplikasi layanan di World Wide Web. Google juga menyediakan source code yang dikenal sebagai Application Programming Interface (API) yang dapat digunakan oleh programmer [12]. Google Map API adalah salah satu API yang paling banyak dipakai didunia. Google maps API terbagi menjadi 4 Platform yaitu Android, iOS, Web dan Webservice. Webservice merupakan layanan yang sifatnya Platform netral karena output dari webservice adalah JSON yang artinya kita bisa membangun aplikasi mobile, web, desktop bahkan embeded system (Seperti GPS tracker di mobil) dengan Google Map API Webservice. Google Maps menawarkan API untuk membangun 
web atau aplikasi berbasis seluler. Google Maps menawarkan API untuk membangun web atau aplikasi berbasis seluler. API Key Google Maps diperlukan untuk mengintegrasikan peta dalam aplikasi [13].

\section{Hasil dan Pembahasan}

Hasil dan pembahasan membahas mengenai uji coba tahapan-tahapan proses, antarmuka, proses input output sistem informasi optimasi distribusi dan uji perbandingan dengan sistem sebelumnya.

\subsection{Perhitungan Rute Terpendek dengan Metode $\mathrm{ClH}$}

Langkah pertama yang dilakukan dalam perhitungan adalah menghitung jarak antar lokasi yang disajikan pada tabel 1.

Tabel 1. Tabel Jarak Antar Lokasi

\begin{tabular}{|l|c|c|c|c|}
\hline \multicolumn{1}{|c|}{ Lokasi } & Gudang 1 & Distributor 1 & Distributor 2 & Distributor 3 \\
\hline Gudang 1 & $\mathbf{0}$ & $\mathbf{1 4 , 8 8}$ & $\mathbf{9 , 7}$ & $\mathbf{7 , 8 9}$ \\
\hline Distributor 1 & $\mathbf{1 4 , 3 7}$ & $\mathbf{0}$ & $\mathbf{8 , 2 6}$ & $\mathbf{8 , 7 4}$ \\
\hline Distributor 2 & $\mathbf{7 , 0 1}$ & $\mathbf{9 , 3 3}$ & $\mathbf{0}$ & $\mathbf{1 , 3 8}$ \\
\hline Distributor 3 & $\mathbf{5 , 9 6}$ & $\mathbf{1 0 , 3}$ & $\mathbf{2 , 8 6}$ & $\mathbf{0}$ \\
\hline
\end{tabular}

Jarak dalam tabel 1 didapatkan dari Google Maps API yang digunakan untuk perhitungan Metode Cheapest Insertion Heuristic dalam menentukan subtour dengan rumus sebagai berikut.

Keterangan :

$$
C j k=C i k+C k j-C i j
$$

$\begin{array}{lll}\mathrm{C}_{\mathrm{ik}} & = & \text { Jarak antara asal dan sisip } \\ \mathrm{C}_{\mathrm{kj}} & = & \text { Jarak antara sisip dan tujuan } \\ \mathrm{C}_{\mathrm{ij}} & = & \text { Jarak antara asal dan tujuan } \\ \mathrm{G} & = & \text { Gudang 1 } \\ \mathrm{A} & = & \text { Distributor 1 } \\ \mathrm{B} & = & \text { Distributor 2 } \\ \mathrm{C} & = & \text { Diatributor 3 }\end{array}$

Subtour adalah perjalanan dari titik pertama dan berakhir di titik pertama sehingga membentuk sebuah sikel, sehingga dapat dilihat pada tabel jarak antar lokasi bahwa terdapat 3 tujuan distribusi yaitu pengiriman berasal dari Gudang 1 - Distributor 1 - Distributor 2 Distributor 3 - Gudang 1. Subtour 1 yang terbentuk yaitu $(G)$ - $(G)$, setelah mendapatkan subtour awal, kemudian tentukan nilai sisip. Nilai sisip diambil dari lokasi yang belum masuk ke dalam subtour, sehingga nilai sisipnya yaitu (A), (B) dan (C). Langkah selanjutnya setelah mendapatkan subtour dan nilai sisip maka rumus dari metode $\mathrm{ClH}$ diimplementasikan dengan menggunakan data jarak antar tabel.

Tabel 2. Subtour $1 \mathrm{G}$ - G

\begin{tabular}{|c|l|c|}
\hline No. & \multicolumn{1}{|c|}{ Rumus } & Nilai \\
\hline 1 & $(G A G)=(G A)+(A G)-(G G)$ & 29,25 \\
\hline 2 & $(G B G)=(G B)+(B G)-(G G)$ & 16,71 \\
\hline 3 & $(G C G)=(G C)+(C G)-(G G)$ & 13,85 \\
\hline
\end{tabular}

Tabel 2 merupakan proses perhitungan subtour 1 dengan 3 nilai sisip menggunakan perhitungan metode $\mathrm{CIH}$. Subtour $(G)$ - $(G)$ dengan nilai sisip $(B)$ menjadi subtour baru yaitu $(G)$ - (B) - (G), untuk implementasi rumus ClH yaitu (GB) merupakan jarak asal dan sisip, (BG) merupakan jarak antara sisip dan tujuan, (GG) merupakan jarak antara asal dan tujuan, sehingga mendapatkan nilai. Nilai yang terkecil merupakan total jarak terpendek dari subtour pada tabel 2 yang kemudian dijadikan subtour baru untuk perhitungan selanjutnya yaitu (G) (B) - (G). 
Tabel 3. Subtour $2 \mathrm{G}$ - B - G

\begin{tabular}{|c|l|c|}
\hline No. & \multicolumn{1}{|c|}{ Rumus } & Nilai \\
\hline 1 & $(G A C)=(G A)+(A C)-(G C)$ & 15,73 \\
\hline 2 & $(G B C)=(G B)+(B C)-(G C)$ & 3,19 \\
\hline 3 & $(C A G)=(C A)+(A G)-(C G)$ & 18,71 \\
\hline 4 & $(C B G)=(C B)+(B G)-(C G)$ & 3,91 \\
\hline 5 & $(G A G)=(G A)+(A G)-(G G)$ & 29,25 \\
\hline 6 & $(G B G)=(G B)+(B G)-(G G)$ & 16,71 \\
\hline
\end{tabular}

Tabel 3 merupakan proses perhitungan untuk menemukan subtour baru dengan 2 nilai sisip menggunakan metode $\mathrm{CIH}$. Subtour $(G)$ - (B) - (G) dipecah menjadi beberapa subtour yaitu $(G)$ - (B), (B) - (G) dan $(G)$ - $(G)$, sehingga pehitungan pada tabel 3 memeliki 3 subtour dengan 2 nilai sisip. Nilai terkecil dari proses perhitungan akan dijadikan sebagai subtour baru pada proses perhitungan selanjutnya yaitu (G) - (B) - (C) - (G).

Tabel 4. Subtour 3 G - B - C - G

\begin{tabular}{|c|l|c|}
\hline No. & \multicolumn{1}{|c|}{ Rumus } & Nilai \\
\hline 1 & $(G A B)=(G A)+(A B)-(G B)$ & 13,44 \\
\hline 2 & $(B A C)=(B A)+(A C)-(B C)$ & 16,69 \\
\hline 3 & $(C A G)=(C A)+(A G)-(C G)$ & 18,71 \\
\hline 4 & $(G A G)=(G A)+(A G)-(G G)$ & 29,25 \\
\hline
\end{tabular}

Tabel 4 merupakan proses perhitungan untuk menemukan subtour baru dengan 1 nilai sisip menggunakan metode $\mathrm{ClH}$. Subtour $(\mathrm{G})$ - $(\mathrm{B})$ - $(\mathrm{C})$ - (G) akan dipecah menjadi beberapa subtour yaitu $(G)$ - (B), (B) - (C), (C) - (G) dan (G) - (G), sehingga pehitungan pada tabel 4 memiliki 4 subtour dengan 1 nilai sisip. Nilai terkecil dari proses perhitungan pada tabel 4 merupakan subtour terpendek yaitu (G) - (A) - (B) - (C) - (G). Perjalanan distribusi dengan jarak terpendek yaitu Gudang 1 - Distributor 1 - Distributor 2 - Distributor 3 - Gudang 1.

\subsection{Uji Coba Proses Sistem}

Uji coba proses penggunaan sistem yang dilakukan adalah tambah distribusi yang dilakukan admin gudang dan proses pengiriman yang dilakukan kurir. Tambah distribusi dilakukan apabila ada pesanan dari distributor. 


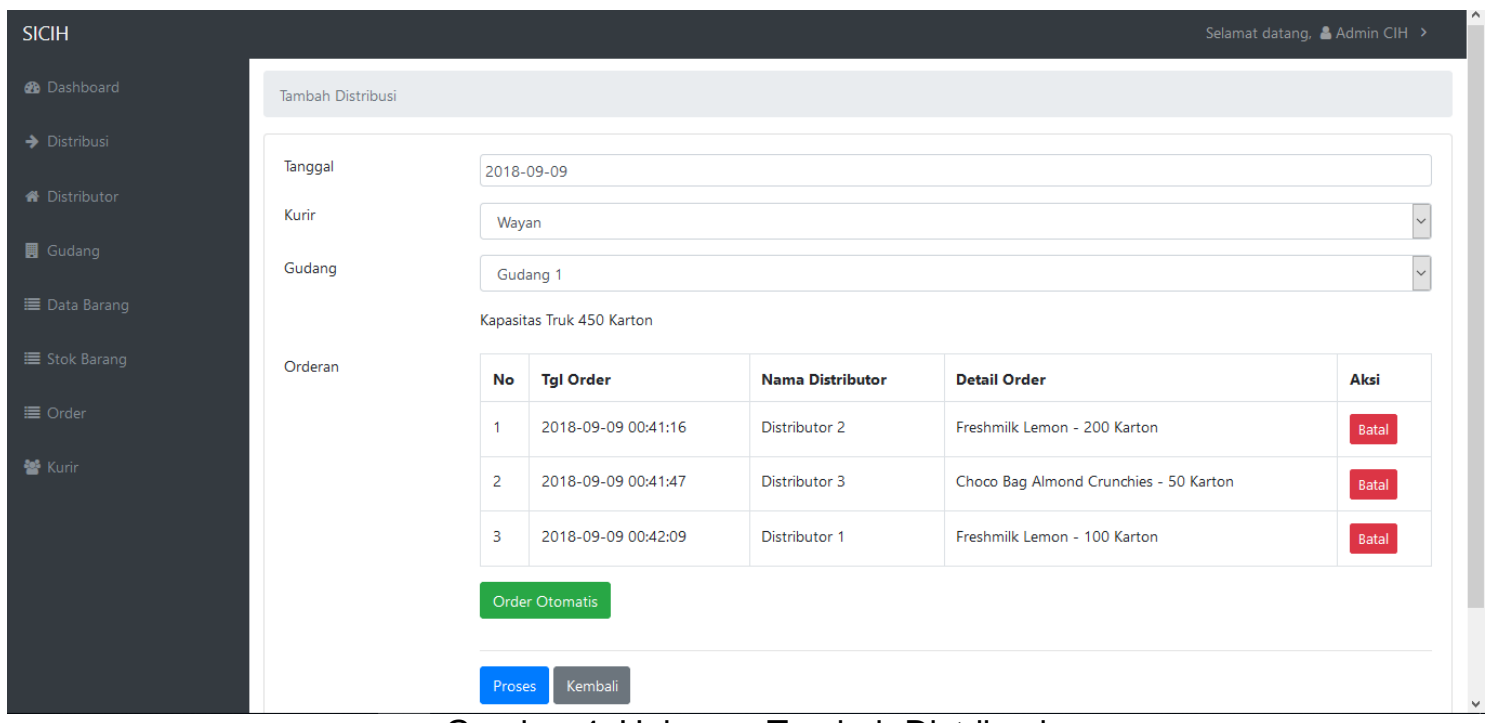

Gambar 4. Halaman Tambah Distribusi

Gambar 4 merupakan halaman untuk menambah distribusi yang dilakukan oleh admin gudang. Proses untuk menambah data distribusi dengan melakukan input tanggal distribusi, memilih kurir, memilih gudang yang dijadikan tempat pengangkutan produk dan memilih distributor yang dikirimkan produk dengan melakukan proses pada kolom aksi. Admin gudang dapat menggunakan fitur order otomatis sehingga tidak perlu memilih distributor satu per satu. Fitur order otomatis diproses berdasarkan tanggal order terlama dan jumlah pesanan sampai memenuhi kapasitas truk pengiriman, ketika kurir memilih fitur order otomatis maka pesanan yang diproses adalah pesanan terlama yang berjumlah kurang dari atau sama dengan 800 karton produk. Tampilan untuk tambah distribusi dapat dilihat pada Gambar 4 yaitu admin gudang melakukan penambahan distribusi pada tanggal 4 September 2018 yang dikirim dari gudang 1, terdapat 3 distributor yang melakukan order produk dengan jumlah pesanan 350 karton. Sistem melakukan perhitungan menggunakan Metode Cheapest Insertion Heuristic untuk menghasilkan rute perjalanan dengan total jarak terpendek.

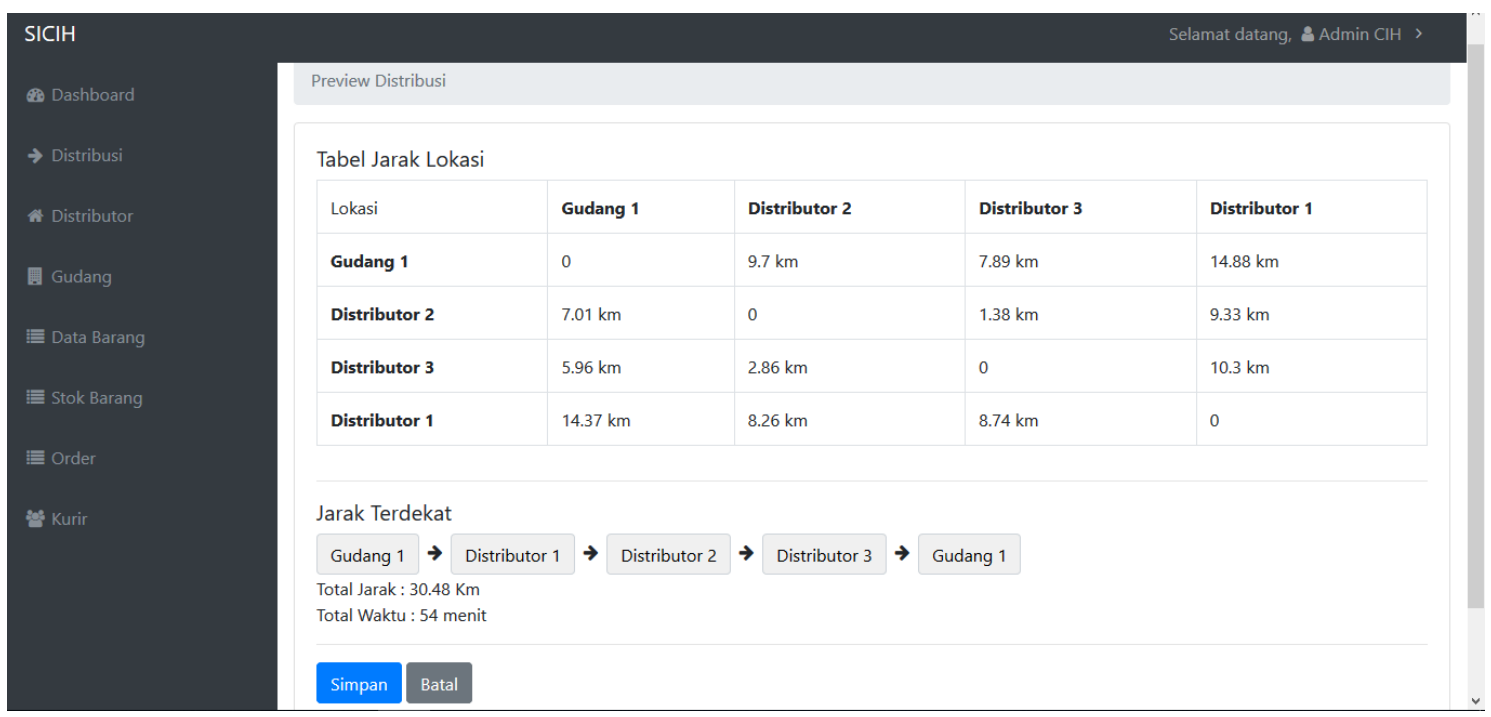

\section{Gambar 5. Halaman Hasil Distribusi}

Gambar 5 merupakan hasil dari proses tambah distribusi yang memberikan informasi berupa tabel jarak masing-masing lokasi, urutan rute distributor yang harus dikunjungi kurir, total jarak perjalanan dan estimasi waktu perjalanan. Urutan rute distribusi yang dihasilkan dimulai dari lokasi awal yaitu Gudang 1 menuju ke 3 distributor 1 kemudian menuju ke distributor 2 kemudian menuju ke distributor 3 dan kembali ke Gudang 1. Total jarak yang harus 
ditempuh untuk 3 lokasi distributor yaitu $30,48 \mathrm{Km}$ dengan total estimasi waktu perjalanan selama 51 Menit. Hasil rute perjalanan pada gambar 5 menunjukan hasil yang sesuai dengan perhitungan menggunakan Metode Cheapest Insertion Heuristic pada subbab 4.1.

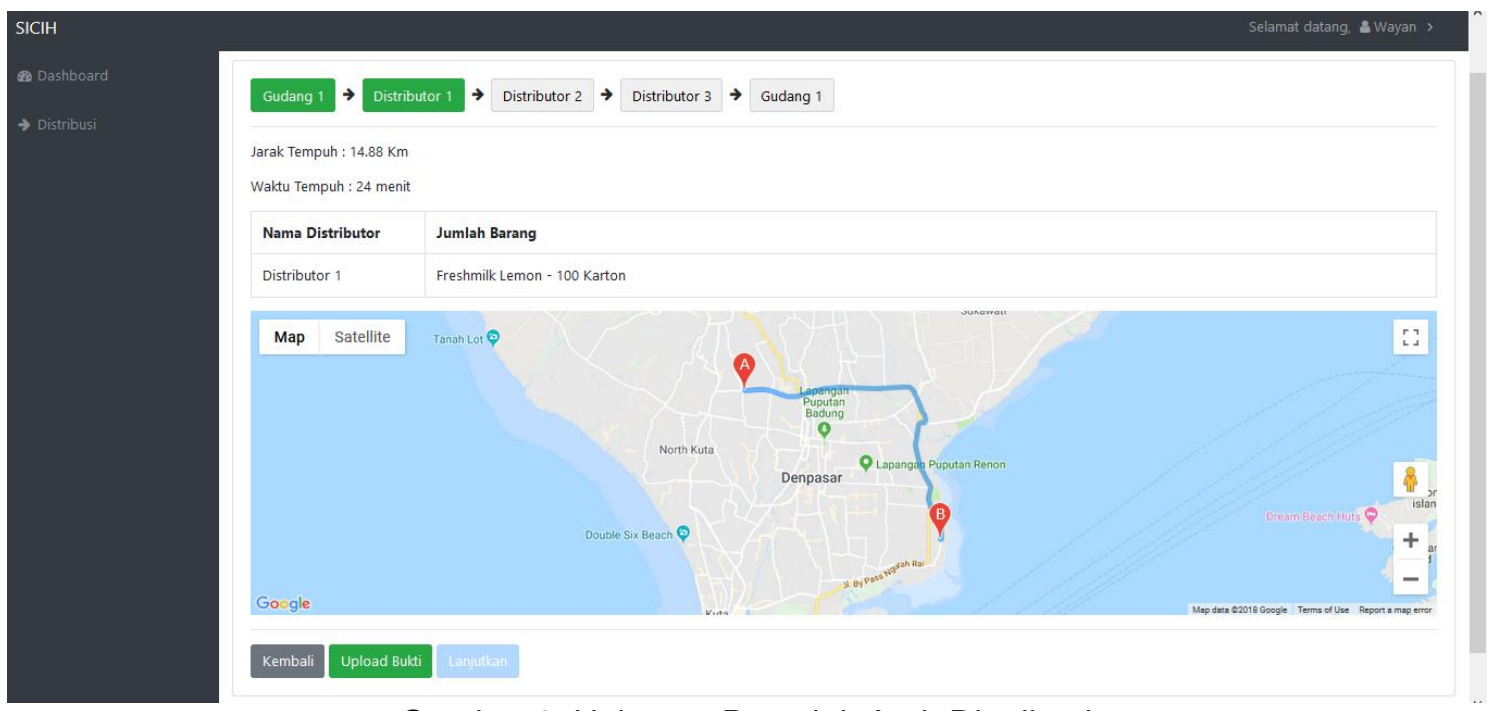

Gambar 6. Halaman Petunjuk Arah Distribusi

Gambar 6 merupakan halaman petunjuk distribusi yang menampilkan visualisasi jalur distribusi dengan memanfaatkan Google Maps. Kurir dapat melihat urutan rute perjalanan distribusi yang dimulai dari lokasi awal yaitu Gudang 1 menuju ke lokasi distributor 1 kemudian menuju ke lokasi distributor 2 kemudian menuju lokasi distributor 3 dan kembali ke Gudang 1. Gambar 6 menunjukkan informasi distribusi dari Gudang 1 menuju ke Distributor 1. Jarak yang harus ditempuh oleh kurir dari Gudang 1 menuju Distributor 1 yaitu 14, $88 \mathrm{Km}$ dengan estimasi waktu perjalanan selama 22 Menit dengan pesanan Freshmilk Lemon sebanyak 100 karton. Jalur yang harus dilalui untuk mengunjungi Gudang 1 yang disimbolkan dengan A menuju ke Distributor 1 yang disimbolkan dengan $B$ ditunjukan dengan garis yang berwarna biru, namun sistem belum dapat mengubah jalur distribusi berdasarkan tingkat kepadatan lalu lintas. Button upload bukti yang berwarna hijau digunakan oleh kurir untuk melakukan upload bukti pengiriman yang sudah ditandatangani oleh distributor penerima produk. Bukti pengiriman harus di-upload setiap kali kurir sampai di lokasi distributor agar kurir dapat melanjutkan proses distribusi dan admin gudang dapat memantau proses distribusi yang dilakukan kurir.

\subsection{Hasil Perbandingan Total Jarak Rute Distribusi Sebelum dan Sesudah} Menggunakan Metode ClH

Sistem penentuan rute pada sebuah perusahaan digunakan sebagai pembanding dengan sistem optimasi distribusi yang menggunakan Metode Cheapest Insertion Heuristic berbasis web. Sistem penentuan rute distrubusi pada sebuah perusahaan menggunakan perkiraan dari petugas pengiriman saja. Informasi urutan rute pada perusahaan tersebut didapat dari hasil wawancara dengan petugas pengiriman. Berikut ini merupakan tabel perbandingan total jarak yang dihasilkan dari sistem optimasi distribusi produk menggunakan Metode Cheapest Insertion Heuristic berbasis web dengan penentuan rute distribusi secara manual di sebuah perusahaan.

Tabel 5.Perbandingan Total Jarak Distribusi Sebelum dan Sesudah Menggunakan Metode CIH

\begin{tabular}{|l|c|l|c|c|c|}
\hline \multirow{2}{*}{ No } & \multirow{2}{*}{$\begin{array}{l}\text { Jumlah } \\
\text { Lokasi }\end{array}$} & \multicolumn{2}{|c|}{ Sesudah Menggunakan Metode CIH } & \multicolumn{2}{c|}{ Sebelum Menggunakan Metode CIH } \\
\cline { 3 - 5 } & 2 Lokasi & Inti Idola Anugerah (Bali) & \multirow{2}{*}{$51,16 \mathrm{~km}$} & Inti Idola Anugerah (Bali) & \multirow{2}{*}{$51,16 \mathrm{~km}$} \\
& & Indomaret Dc Denpasar & & Indomaret Dc Denpasar & \\
\hline
\end{tabular}




\begin{tabular}{|c|c|c|c|c|c|}
\hline \multirow[t]{3}{*}{2} & \multirow[t]{3}{*}{3 Lokasi } & Tiara Dewata & \multirow{3}{*}{$52,93 \mathrm{~km}$} & Tiara Dewata & \multirow{3}{*}{$52,93 \mathrm{~km}$} \\
\hline & & Circle K Denpasar S & & Circle K Denpasar S & \\
\hline & & Indomaret Dc Denpasar & & Indomaret Dc Denpasar & \\
\hline \multirow[t]{4}{*}{3} & \multirow[t]{4}{*}{4 Lokasi } & Pepito Hayam Wuruk & \multirow{4}{*}{$24,44 \mathrm{~km}$} & Tiara Dewata & \multirow{4}{*}{$26,10 \mathrm{~km}$} \\
\hline & & Toko Salam Renon & & Circle K Denpasar S & \\
\hline & & Tiara Dewata & & Toko Salam Renon & \\
\hline & & Circle K Denpasar S & & Pepito Hayam Wuruk & \\
\hline \multirow[t]{5}{*}{4} & \multirow[t]{5}{*}{5 Lokasi } & Good Food Frozen & \multirow{5}{*}{$32,61 \mathrm{~km}$} & Lotte Shopping Denpasar & \multirow{5}{*}{$38,90 \mathrm{~km}$} \\
\hline & & Trans Retail Ind (Sunset) & & Trans Retail Ind (Sunset) & \\
\hline & & Lotte Shopping Denpasar & & Good Food Frozen & \\
\hline & & Foodmart Primo Level 21 & & Foodmart Primo Level 21 & \\
\hline & & Circle K Denpasar S & & Circle K Denpasar S & \\
\hline \multirow[t]{6}{*}{5} & \multirow[t]{6}{*}{6 Lokasi } & Pepito Hayam Wuruk & \multirow{6}{*}{$45,8 \mathrm{~km}$} & Hypermart Simpang Siur & \multirow{6}{*}{$49,52 \mathrm{~km}$} \\
\hline & & Hypermart Simpang Siur & & Lotte Shopping Denpasar & \\
\hline & & Lotte Shopping Denpasar & & Pepito Hayam Wuruk & \\
\hline & & Foodmart Primo Level 21 & & Bj Food Mart & \\
\hline & & Bj Food Mart & & Foodmart Primo Level 21 & \\
\hline & & Circle K Denpasar S & & Circle K Denpasar S & \\
\hline \multirow[t]{7}{*}{6} & \multirow[t]{7}{*}{7 Lokasi } & Lotte Shopping Denpasar & \multirow{7}{*}{$35,43 \mathrm{~km}$} & Ud. Setia Perdana & \multirow{7}{*}{$44,10 \mathrm{~km}$} \\
\hline & & Ramayana Bali & & Lotte Shopping Denpasar & \\
\hline & & Ramayana Sesetan & & Ramayana Sesetan & \\
\hline & & Ramayana Bali II & & Foodmart Primo Level 21 & \\
\hline & & Foodmart Primo Level 21 & & Ramayana Bali II & \\
\hline & & Circle K Denpasar S & & Ramayana Bali & \\
\hline & & Ud. Setia Perdana & & Circle K Denpasar S & \\
\hline 7 & 8 Lokasi & Toko Salam Renon & & Tiara Dewata & \\
\hline & & Lotte Shopping Denpasar & & Lotte Shopping Denpasar & \\
\hline & & Nine Mart & & Nine Mart & \\
\hline & & Ramayana Bali II & & Toko Salam Renon & \\
\hline & & Ramayana Bali & 32,64 km & Circle K Denpasar S & $47,71 \mathrm{~km}$ \\
\hline & & Circle K Denpasar S & & Ramayana Bali II & \\
\hline & & Tiara Dewata & & Ramayana Bali & \\
\hline & & Toko Monang Maning & & Toko Monang Maning & \\
\hline 8 & 9 Lokasi & Pepito Hayam Wuruk & & Tiara Dewata & \\
\hline & & Toko Salam Renon & & Pepito Hayam Wuruk & \\
\hline & & Hardys Sanur & & Toko Salam Renon & \\
\hline & & Lotte Shopping Denpasar & & Hardys Sanur & \\
\hline & & Ramayana Bali & $40.71 \mathrm{Km}$ & Lotte Shopping Denpasar & $42,71 \mathrm{~km}$ \\
\hline & & Ramayana Sesetan & & Ramayana Bali II & \\
\hline & & Ramayana Bali II & & Ramayana Sesetan & \\
\hline & & Foodmart Primo Level 21 & & Ramayana Bali & \\
\hline & & Tiara Dewata & & Foodmart Primo Level 21 & \\
\hline 9 & 10 Lokasi & Pepito Lovina & & Pepito Seminyak & \\
\hline & & Pepito Seminyak & & Pepito Dewi Sri & \\
\hline & & Pepito Dewi Sri & & Papaya & \\
\hline & & Papaya & & Pepito Lovina & \\
\hline & & Pepito Kediri Tuban & & Pepito Kediri Tuban & \\
\hline & & Pepito Canggu Deli & $189,25 \mathrm{~km}$ & $\begin{array}{l}\text { Burger King Discovery } \\
\text { Shopping }\end{array}$ & $241,63 \mathrm{~km}$ \\
\hline & & $\begin{array}{l}\text { Burger King Discovery } \\
\text { Shopping }\end{array}$ & & Burger King Kuta Square & \\
\hline & & Burger King Kuta Square & & Pepito Canggu & \\
\hline & & Pepito Eco Beach & & Pepito Canggu Deli & \\
\hline & & Pepito Canggu & & Pepito Eco Beach & \\
\hline
\end{tabular}

Tabel 5 merupakan uji coba perbandingan total jarak sistem optimasi distribusi menggunakan Metode Cheapest Insertion Heuristic dengan sistem penentuan rute sebuah perusahaan. Perbandingan dilakukan untuk membuktikan sistem optimasi distribusi menggunakan Metode Cheapest Insertion Heuristic dapat dikatakan optimal atau tidak. Hasil dari uji coba menunjukan Metode Cheapest Insertion Heuristic dapat dikatakan optimal dari segi jarak tempuh perjalanan karena total jarak yang dihasilkan Metode Cheapest Insertion Heuristic lebih pendek dibandingkan dengan penentuan rute secara manual pada sebuah perusahaan. 


\section{Kesimpulan}

Perancangan dan pembangunan optimasi distribusi berbasis web memanfaatkan Google Maps API untuk melakukan proses pengolahan data latitude dan longitude yang sudah tersimpan pada database agar dapat menampilkan peta lokasi distributor, data jarak antar lokasi, jalur distribusi, jarak tempuh dan estimasi waktu tempuh perjalanan distribusi. Hasil pengujian membuktikan bahwa Metode Cheapest Insertion Heuristic telah mampu diterapkan dalam pembangunan sistem optimasi distribusi pada sebuah perusahan. Penerapan Metode Cheapest Insertion Heuristic mampu menghasilkan rute perjalanan yang optimal dengan total jarak yang lebih pendek dibandingkan dengan sistem penentuan rute distribusi berdasarkan perkiraan pada sebuah perusahaan.

\section{Daftar Pustaka}

[1] R. Sulistiorini and W. F. Mahmudy, "Penerapan algoritma evolution strategies untuk optimasi distribusi barang dua tahap," Repos. J. Mhs., 2015.

[2] A. W. Nirwansyah, Dasar Sistem Informasi Geografi dan Aplikasinya Menggunakan ARCGIS 9.3. Yogyakarta, 2017.

[3] S. Rahayu, I. N. Piarsa, and P. W. Buana, "Sistem Informasi Geografis Pemetaan Daerah Aliran Sungai Berbasis Web," Lontar Komput. J. IIm. Teknol. Inf., vol. 7, no. 2, p. 71, 2016.

[4] S. Yilmaz and C. M. Seifert, "Creativity through design heuristics: A case study of expert product design," Des. Stud., 2011.

[5] A. R. Fauzi and S. Susanty, "Penentuan Rute Distribusi Tabung Gas Menggunakan Metode ( 1-0 ) Insertion Intra Route," J. Online Inst. Teknol. Nas., vol. 03, no. 01, pp. 318-328, 2015.

[6] P. W. Buana, "Penemuan rute terpendek pada aplikasi berbasis peta," Lontar Komput., vol. 1, no. 1, pp. 1-8, 2010.

[7] S. Supriyadi, K. Mawardi, and A. Nalhadi, "Minimasi Biaya Dalam Penentuan Rute Distribusi Produk Minuman Menggunakan Metode Savings Matrix," Semin. Nas. Inst. Supply Chain dan Logistik Indones., no. September, pp. 1-7, 2017.

[8] C. Nelwan, J. S. Kekenusa, and Y. Langi, "Optimasi Pendistribusian Air Dengan Menggunakan Metode Leave Cost dan Metode Modified Distribution," J. IIm. Sains, vol. 13, no. 1, pp. 45-51, 2013.

[9] R. Effendi and S. Maulinda, "Studi Perbandingan Algoritma Cheapest Insertion Heuristic Dan Ant Colony System Dalam Pemecahan Travelling Salesman," Semin. Nas. Apl. Teknol. Inf., vol. 2010, no. Snati, pp. 1-6, 2010.

[10] M. P. Ika Lis Mariatun, "Pengaruh Saluran Distribusi, Harga Dan Promosi Terhadap Volume Penjualan Pada Home Industri Tempe Putra KI Kecamatan Socah Tahun 2016," J. IImu dan Pendidik. Ekon. ISSN, 2017.

[11] Kusrini and Jazi Eko Istiyanto, "Penyelesaian Travelling Salesman Problem Dengan Algoritma Cheapest Insertion Heuristics Dan Basis Data," J. Inform., vol. 8, no. 2, pp. 109-114, 2017.

[12] I. N. Piarsa, E. S. Hadi, N. Kadek, and A. Wirdiani, "Rural Road Mapping Geographic Information System Using Mobile Android," Int. J. Comput. Sci. Issues, vol. 12, no. 3, pp. 95-100, 2015.

[13] A. Rahmi, I. N. Piarsa, and P. W. Buana, "FinDoctor - Interactive Android Clinic Geographical Information System Using Firebase and Google Maps API," Int. J. New Technol. Res., vol. 3, no. 7, pp. 8-12, 2017. 